\title{
THE NEW FM GLOBAL TECHNOLOGY CENTER
}

\author{
PAUL A. CROCE \\ FM Global Research, Norwood, Massachusetts, USA 02062
}

\begin{abstract}
At a time when many companies are canceling expansion plans, FM Global has broken ground on a new US\$70 million-plus research and product-testing center to meet customers' changing property protection needs and to advance the ever-evolving science of property protection. The new FM Global Technology Center, a world-class complex that represents the largest investment FM Global has ever made in its research and testing programs, will vastly expand FM Global's capabilities, as well as its understanding of a wide variety of property hazards.
\end{abstract}

The modernization project, which includes the construction of three new buildings housing numerous laboratories for research and materials, natural hazards and electrical testing, is expected to be completed and in operation by the fall of 2003 . The new facilities are part of a major upgrade to the renowned FM Global Test Center in West Glocester, RI, USA. The Test Center, which was built in 1967, will remain operational throughout the construction period.

Constant advances in technology, increasingly sophisticated customer needs, and the ever-changing science of property loss prevention and control demanded that FM Global modernize its research and testing facilities. Additionally, with FM Global's research and testing operations currently located in three different states, huge benefits are derived by having new state-of-the-art facilities and the majority of the company's research and product-testing laboratories centralized on one campus. The new laboratories will enable FM Global to increase its research focus beyond traditional areas, and both internal and external customers can expect faster turnaround times to their needs and more advanced solutions that help reduce property risks.

The cornerstone of the expansion will be the construction of a $108,000-\mathrm{ft}^{2}\left(10,200-\mathrm{m}^{2}\right)$ research and materials facility that will be twice as large as the existing test center and boast many improvements. The most prominent area of the new facility will be a 33,000$\mathrm{ft}^{2}\left(10,034-\mathrm{m}^{2}\right)$ large-burn laboratory. It will be two million $\mathrm{ft}^{3}\left(609,600 \mathrm{~m}^{3}\right)$ in volume and house two major fire-test site pads, and a large movable 80-ft (24-m) square ceiling. Each test site will be equipped to make combustion product measurements, including heat release rate, throughout the duration of large fire tests, allowing correlations with fire behavior from ignition, through spread and growth to full involvement and suppression.

In addition, the new burn laboratory will contain a 20-megawatt (MW) fire products collector, with an airflow of $240,000 \mathrm{scfm}\left(113 \mathrm{~m}^{3} / \mathrm{S}\right)$, used for commodity classification and for assessing the fire hazard of products and storage arrangements. This calorimeter will be four-times larger than the existing calorimeter, providing the capability to study a broader range of commodities, as well as larger commodity arrangements. 
The facility's other features will include several smaller laboratories for intermediateand small-scale burn testing, which will include two movable ceilings and three additional fire calorimeters, including the 5-MW instrument from the existing test center, a 1-MW system and a 0.2-MW unit. Dedicated test spaces will be allocated for research and testing of fire protection technology and for simulating unique types of environments that require customized solutions. New tests, such as the Single Burning Item (SBI) test, soon to become standard throughout Europe, also will be introduced.

The new facility is designed so that numerous fire tests, from small- to large-scale, can be conducted simultaneously throughout the day without interrupting other work, which translates to timelier loss prevention solutions and speedier testing and Approvals.

The research and materials laboratory is also being built with visitors foremost in mind, whether it is FM Global insureds, industry experts, students, Approvals clients or the public. The visitor-friendly facility will feature modern meeting and training rooms for up to 150 people and allow easy viewing of the building's laboratories.

Because natural hazards - like windstorms, floods and earthquakes - cause major property damage world wide, a significant part of the project includes the addition of a $12,000-\mathrm{ft}^{2}\left(1,115-\mathrm{m}^{2}\right)$ natural hazards laboratory for testing building materials. This testing, currently being done at labs in Norwood, Mass., USA, and Putnam, Conn., USA, will be moved to this facility. This lab will be able to duplicate the natural hazard exposures for a building, like windblown debris, wind-driven rain and weather extremes, and freezing and thawing, as well as to accelerate the weathering of materials to better determine long-term performance. In addition to current offerings such as wind uplift, hail damage and other environmental durability testing, one of the greatest gains at this new facility will be the capability to conduct a more thorough analysis of building materials for property owners. The lab will have the ability to recreate real wind with hurricane-force speeds of up to $160 \mathrm{mph}(258 \mathrm{~km} / \mathrm{h})$ to more accurately determine the performance of windows, doors, walls and roofing materials. In addition, water can be added to replicate the effects of wind-driven rain, rather than simulated wind-uplift tests that use suction devices.

Other key features of the new FM Global Technology Center include a new 6,000- $\mathrm{ft}^{2}$ $\left(1,829-\mathrm{m}^{2}\right)$ laboratory to test explosion-proof and flameproof electrical equipment for use in hazardous locations, and a relocated demonstration area and test system to illustrate the potentially devastating effects of dust explosions. Further, the site will be supported by state-of-the-art environmental controls, including WESP-based air emission control technology, coupled with a new and sophisticated approach to air-handling and ventilation for fire testing, as well as a closed-loop test water system.

Research and testing is an integral part of FM Global and its future. With the FM Global Technology Center, we have designed facilities to meet the current needs and to serve us for at least the next 30 years. No other organization will have facilities like these. Understanding property hazards, developing new and improved solutions for our customers and testing new products to prevent or reduce loss is central to the value we provide our customers. This investment to build the best facilities with leading-edge capabilities underscores that commitment. 